\title{
Evodiamine induces reactive oxygen species-dependent apoptosis and necroptosis in human melanoma A-375 cells
}

\author{
NING LIU ${ }^{1,2}$, YONGXI LI ${ }^{1}$, GUANZHI CHEN ${ }^{2}$ and KELI GE ${ }^{3}$ \\ ${ }^{1}$ Department of Dermatology, The Affiliated Qingdao Municipal Hospital of Qingdao University, Qingdao, Shandong 266011; \\ ${ }^{2}$ Department of Dermatology, The Affiliated Hospital of Qingdao University, Qingdao, Shandong 266000; \\ ${ }^{3}$ Institute of Integrated Medicine, Medical College, Qingdao University, Qingdao, Shandong 266023, P.R. China
}

Received January 10, 2020; Accepted June 25, 2020

DOI: 10.3892/ol.2020.11983

\begin{abstract}
Melanoma is a common solid malignant tumor with a high frequency of metastasis and relapse. Evodiamine (EVO), a natural small molecule, has recently attracted considerable attention due to its pharmacological action, including its anticancer effects. However, the mechanism of the cytotoxic effect exerted by EVO on tumor cells is not yet fully understood. The present study aimed to evaluate the antitumor effects of evodiamine in human melanoma A-375 cells. The results demonstrated that EVO inhibited cell proliferation and induced cell cycle arrest at the $\mathrm{G}_{2} / \mathrm{M}$ stage in human melanoma A-375 cells. The results also revealed that EVO exposure induced the activation of caspase-3, caspase- 9 and poly (ADP-ribose) polymerase 1 , as well as mitochondrial membrane potential dissipation in a time-dependent manner, indicating that EVO induced intrinsic apoptosis in A-375 cells. Furthermore, the results revealed that receptor-interacting serine/threonine kinase (RIP) and RIP3 were sequentially activated, suggesting that necroptosis may also be involved in EVO-induced cell death in A-375 cells. In addition, co-treatment with catalase was demonstrated to significantly attenuate the EVO-induced cell death in A-375 cells, indicating that reactive oxygen species (ROS) may serve an important role in EVO-induced cell death. In conclusion, the results of the present study unveiled a novel mechanism of drug action by EVO in human melanoma cells and suggested its potential value in treating human melanoma by inducing cell death via ROS activation.
\end{abstract}

Correspondence to: Dr Keli Ge, Institute of Integrated Medicine, Medical College, Qingdao University, 38 Dengzhou Road, Qingdao, Shandong 266023, P.R. China

E-mail:ntfadu@163.com

Dr Guanzhi Chen, Department of Dermatology, The Affiliated Hospital of Qingdao University, 16 Jiangsu Road, Qingdao, Shandong 266000, P.R. China

E-mail: guanzhichenz@sina.com

Key words: evodiamine, melanoma, reactive oxygen species, apoptosis, necroptosis

\section{Introduction}

Melanoma is a common solid malignant tumor that has a high frequency of metastasis and relapse; in 2018, 287,723 new cases of melanoma and 60,712 deaths were registered worldwide, ranking as the 21st most common type of cancer worldwide (1). High incidence of melanoma has become a serious threat to human health worldwide. Traditional therapeutic interventions including chemotherapy, radiotherapy and surgery cannot effectively increase the overall survival time of patients with melanoma, particularly those in advanced stages (2). Thus, it is crucial to find novel strategies to further improve the outcome of melanoma therapy.

Evodiamine (EVO), a quinolone alkaloid derived from the fruit of Evodia rutaecarpa (Chinese name, Wu-Zhu-Yu) that has been used in traditional Chinese medicine to treat headache and gastrointestinal disorders (3), has been demonstrated to exert various biological effects including testosterone secretion (4), catecholamine secretion (5), antinociceptive (6), anti-inflammatory (7), antiobesity (8), vasodilatory (9), thermoregulatory (10) and uterotonic (11) effects. Numerous studies have revealed that EVO exhibited antitumor activity by inhibiting the proliferation, inducing cell cycle arrest and apoptosis, and decreasing the invasion and migration of a variety of tumor cells (12-18). In addition, the cytotoxicity of EVO is tumor-specific, as demonstrated by EVO inducing limited toxicity in normal human peripheral blood cells (14).

Reactive oxygen species (ROS), which have been aptly described as a heterogeneous group of diatomic oxygen from free and non-free radical species, have been implicated as mediators of various biological processes, such cell proliferation, inflammation and aging (19). Depending on the levels, ROS is referred to as a 'double-edged sword' in tumor cells: Persistent high levels of ROS compared with normal cells often leads to increased cell proliferation and adaptive responses that may contribute to tumorigenesis, metastasis and treatment resistance; however, further exposure to exogenous ROS results in tumor cell death $(20,21)$. Redox biology, especially ROS, serves a central role in all aspects of melanoma pathophysiology, including initiation, progression and metastasis (22). EVO induces oxidative stress by increasing ROS generation, as demonstrated by previous studies $(23,24)$; however, the association between ROS and EVO-induced cell death remains unclear. 
The present study aimed to investigate the effects of EVO in human melanoma A-375 cells and the roles of ROS in EVO-induced cell death.

\section{Materials and methods}

Reagents. EVO was supplied by MedChemExpress and was dissolved $(50 \mathrm{mM})$ in dimethyl sulfoxide (DMSO) and stored at $-80^{\circ} \mathrm{C}$. The concentration of DMSO used for control treatments was based on the highest concentration of EVO in each experiment. All other reagents were purchased from Sigma-Aldrich; Merck KGaA, with the exception of Z-VAD-fmk and Nec-1, which were also purchased from MedChemExpress.

Cell culture. A-375 cells was obtained from the National Infrastructure of Cell Line Resource and maintained under standard culture conditions $\left(37^{\circ} \mathrm{C}, 5 \% \mathrm{CO}_{2}\right)$ in RPMI- 1640 medium with $10 \%$ fetal bovine serum (Gibco; Thermo Fisher Scientific, Inc.).

CCK-8 cell viability assay. A-375 cells were seeded into a 96-well plate at $1 \times 10^{4}$ cells per well with $100 \mu \mathrm{l}$ culture medium and cultured at $37^{\circ} \mathrm{C}$ with $5 \% \mathrm{CO}_{2}$. A-375 cells were treated with DMSO or 5-15 $\mu \mathrm{M}$ EVO for 24,48 and $72 \mathrm{~h}$, or pretreated with $100 \mu \mathrm{M}$ Z-VAD-fmk, $50 \mu \mathrm{M}$ Nec-1 or $2,000 \mathrm{U} / \mathrm{ml}$ catalase for $1 \mathrm{~h}$ prior to treatment with $10 \mu \mathrm{M} \mathrm{EVO}$ for $24 \mathrm{~h}$. After treatment, the medium was replaced with $10 \%$ Cell Counting Kit-8 (Dojindo Laboratories)-containing medium and incubated for $2 \mathrm{~h}$ at $37^{\circ} \mathrm{C}$ with $5 \% \mathrm{CO}_{2}$. Following incubation, the plates were scanned using a Power Wave XS microplate reader (BioTek Instruments, Inc.), and the absorbance at $450 \mathrm{~nm}$ was recorded.

Determination of intracellular ROS. Intracellular ROS levels were determined using a DCFH-DA kit (Beyotime Institute of Biotechnology). In brief, A-375 cells were seeded in the 6-well plates $\left(2 \times 10^{5}\right.$ cells/well $)$ and treated with DMSO, $10 \mu \mathrm{M}$ EVO or $2,000 \mathrm{U} / \mathrm{ml}$ catalase for $24 \mathrm{~h}$, or pretreated with catalase $(2,000 \mathrm{U} / \mathrm{ml}, 2 \mathrm{~h}$ pre-treatment $)$ and incubated in the medium containing $10 \mu \mathrm{M}$ EVO and 2,000 U/ml catalase for $24 \mathrm{~h}$. After treatment, the cells were harvested by trypsinization and centrifugation $\left(120 \mathrm{xg}\right.$ for $5 \mathrm{~min}$ at $\left.4^{\circ} \mathrm{C}\right)$, incubated with $50 \mu \mathrm{M}$ DCFH-DA solution at $37^{\circ} \mathrm{C}$ in the dark for $30 \mathrm{~min}$ and subjected to analysis using a BD Accuri C6 flow cytometer with BD Accuri C6 software v1.0.264.21 (BD Biosciences).

Cell cycle and apoptosis assays. A-375 cells were seeded in 6 -well plates $\left(2 \times 10^{5}\right.$ cells/well $)$ and treated with DMSO or $10 \mu \mathrm{M} \mathrm{EVO}$ for $24 \mathrm{~h}$. After treatment, the cells were harvested by trypsinization and centrifugation $(120 \mathrm{x} \mathrm{g}$ for $5 \mathrm{~min}$ at $4^{\circ} \mathrm{C}$ ), and fixed with $70 \%$ ethanol at $4^{\circ} \mathrm{C}$ for $\geq 12 \mathrm{~h}$. After rinsing twice with phosphate buffer solution (PBS), the cells were re-suspended in a DNA staining solution containing $40 \mathrm{mg} / \mathrm{ml}$ propidium iodide (PI) and $0.1 \mathrm{mg} / \mathrm{ml} \mathrm{RNase}$ (Beyotime Institute of Biotechnology) at room temperature in the dark for $30 \mathrm{~min}$. The cells were analyzed with a BD Accuri C6 Flow Cytometer (BD Biosciences) equipped with the FlowJo software (FlowJo vX; FlowJo LLC). Then, the cell cycle distribution was determined.

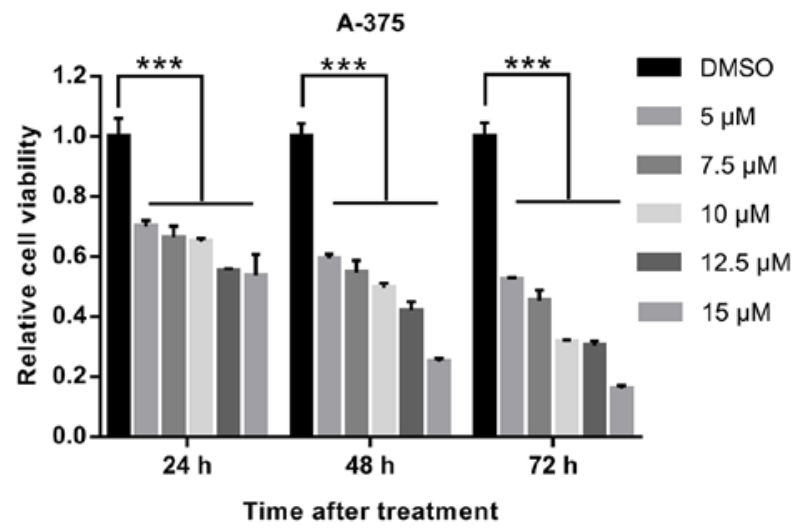

Figure 1. Evodiamine inhibits the viability of human melanoma A-375 cells. A-375 cells were treated with DMSO and evodiamine for 24, 48 and $72 \mathrm{~h}$, and the cell viability was measured by Cell Counting Kit- 8 assay. ${ }^{* * *} \mathrm{P}<0.001$ vs. DMSO.

For the apoptosis assay, A-375 cells were treated with DMSO $(24 \mathrm{~h})$, or EVO $(10 \mu \mathrm{M})$ for 12 and $24 \mathrm{~h}$, then the cells were harvested by trypsinization and centrifugation $\left(120 \mathrm{x} \mathrm{g}\right.$ for $5 \mathrm{~min}$ at $\left.4^{\circ} \mathrm{C}\right)$. After rinsing twice with PBS, the cells were re-suspended in a solution containing Annexin-V and PI (EpiZyme Biotech), and the cells were analyzed with a BD Accuri C6 Flow Cytometer and BD Accuri C6 software.

Western blot analysis. A-375 cells were seeded in the $10-\mathrm{cm}$ dishes $\left(1.2 \times 10^{6}\right.$ cells/dish). The cells were treated with DMSO for $24 \mathrm{~h}$ or with $10 \mu \mathrm{M}$ EVO for 3, 6, 9, 12 and $24 \mathrm{~h}$. After treatment, the cells were rinsed with PBS $\left(4^{\circ} \mathrm{C}\right.$ ). The cells were lysed with RIPA lysis buffer (Beyotime Institute of Biotechnology) at $4^{\circ} \mathrm{C}$ for $30 \mathrm{~min}$ and centrifuged $(12,000 \mathrm{x} \mathrm{g})$ at $4^{\circ} \mathrm{C}$ for $15 \mathrm{~min}$. For each treatment group, $40 \mu \mathrm{g}$ protein determined using BCA assay (Beyotime Institute of Biotechnology) was separated by SDS-PAGE (10-12\% gel) and transferred to a PVDF membrane. After blocking in 5\% non-fat milk for $1 \mathrm{~h}$, the membrane was incubated with the primary antibodies at $4^{\circ} \mathrm{C}$ overnight, with the exception of $\beta$-actin, which was used for an incubation of $1 \mathrm{~h}$ at room temperature. The antibodies against phosphorylated (p-) cell division cycle (cdc) 2 (cat. no. 9114), cdc2 (cat. no. 77055), cyclin B1 (cat. no. 12231), cdc25C (cat. no. 4688), caspase-3 (cat. no. 14220), caspase-9 (cat. no. 9502), poly (ADP-ribose) polymerase 1 (PARP-1; cat. no. 9532), BCL2 (cat. no. 4223), BAX (cat. no. 5023), p-receptor-interacting serine/threonine kinase (RIP; cat. no. 65746), RIP (cat. no. 3493), p-RIP3 (cat. no. 93654) and RIP3 (cat. no. 13526) were purchased from Cell Signaling Technology, Inc., and the antibody against $\beta$-actin (cat. no. AC028) was purchased from ABclonal Biotech Co., Ltd. The primary antibodies were diluted $(1: 1,000)$ with TBS-0.5\% Tween-20 (TBS-T) buffer with 5\% BSA (Beyotime Institute of Biotechnology), with the exception of horseradish peroxidase (HRP)-conjugated $\beta$-actin, which was diluted $(1: 5,000)$ with TBS-T buffer with $5 \%$ non-fat milk. The secondary antibody, HRP Goat Anti-Rabbit IgG $(\mathrm{H}+\mathrm{L})$ (cat. no. AS014), was purchased from ABclonal Biotech Co., Ltd., and diluted $(1: 5,000)$ with TBS-T buffer with $5 \%$ non-fat milk. The signals were detected using an enhanced 

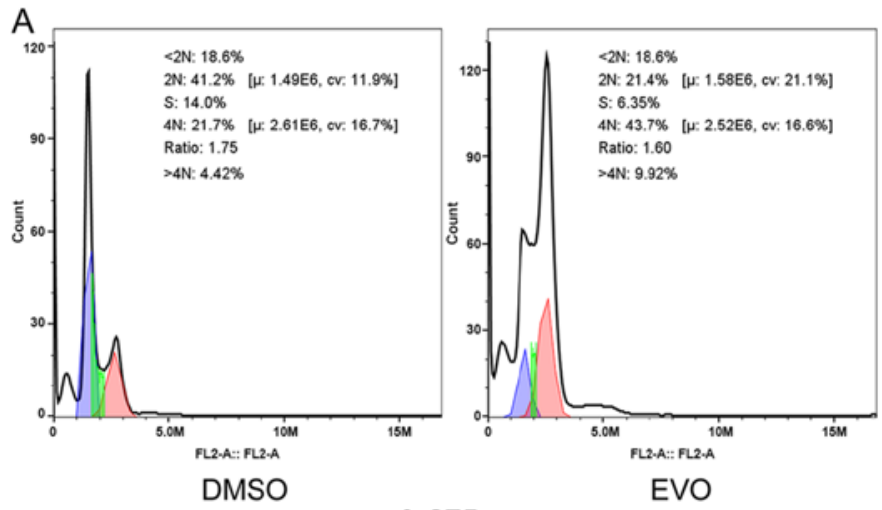

A-375

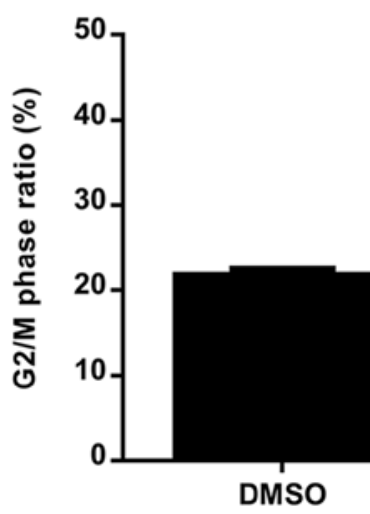

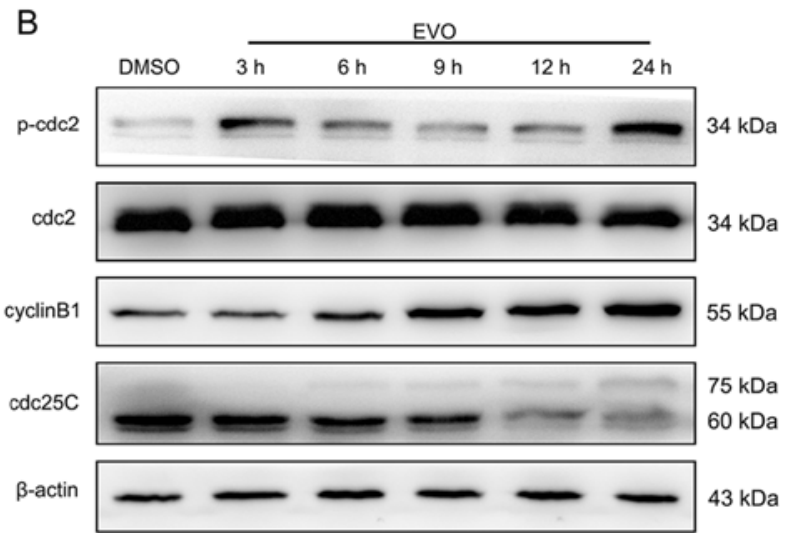

Figure 2. EVO induces $\mathrm{G}_{2} / \mathrm{M}$ cell cycle arrest in A-375 cells. (A) PI staining assay of A-375 cells treated with DMSO or $10 \mu \mathrm{M}$ EVO for $24 \mathrm{~h}$ examined by flow cytometry. (B) A-375 cells were treated with DMSO or $10 \mu \mathrm{M}$ EVO for 3, 6, 9, 12 or $24 \mathrm{~h}$, and the levels of p-cdc2 (Thr161), cdc2, cyclin B1 and cdc25C were examined by western blotting. ${ }^{* * *} \mathrm{P}<0.001$ vs. DMSO. EVO, evodiamine; PI, propidium iodide; cdc, cell division cycle; $\mathrm{p}-$, phosphorylated.

chemiluminescence system (Beijing Kechuang Ruixin Biotechnology Co., Ltd.) and quantified by ImageJ software (v1.8.0; National Institutes of Health). Representative blots and quantification from three independent experiments are presented in the figures.

Mitochondrial membrane potential $(\Delta \psi m)$ assay. Similar to the cell cycle assay, A-375 cells were harvested, and a Mitochondrial Membrane Potential Assay kit with JC-1 (Beyotime Institute of Biotechnology) was used for the analysis of $\Delta \psi \mathrm{m}$ according to the manufacturer's instructions. J-aggregates emitted red fluorescence in cells with a high $\Delta \psi \mathrm{m}$, whereas the JC-1 monomer emitted green fluorescence in cells with a low $\Delta \psi \mathrm{m}$. The value of $\Delta \psi \mathrm{m}$ was expressed as the ratio of red to green fluorescence intensity.

Statistical analysis. Data are presented as the mean \pm standard error. Statistical analysis was performed by GraphPad Prism 7 software (GraphPad Software, Inc.) using Student's t-test for two-group comparisons or one-way ANOVA followed by Dunnett's post hoc test for comparisons between treatment and control groups or by Tukey's test for comparisons among multiple groups. $\mathrm{P}<0.05$ was considered to indicate a statistically significant difference.

\section{Results}

EVO inhibits A-375 cell proliferation. A CCK-8 assay was used to evaluate the effects of EVO on the proliferation of human melanoma A-375 cells. As presented in Fig. 1 and Table SI,
EVO inhibited cell proliferation in a dose- and time-dependent manner, and $10 \mu \mathrm{M}$ was selected for further experiments.

EVO induces $G_{2} / M$ cell cycle arrest in A-375 cells. Since cell cycle arrest serves an important role in cell proliferation inhibition, the cell cycle was assessed using flow cytometry in the present study. As presented in Fig. 2A, the cell cycle of A-375 cells exposed to EVO $(10 \mu \mathrm{M}, 24 \mathrm{~h})$ was selectively arrested in the $\mathrm{G}_{2} / \mathrm{M}$ phase. Further results demonstrated that EVO treatment appeared to increase the phosphorylation levels of cdc2 at 3 and $24 \mathrm{~h}$ compared with those in the DMSO control, indicating that EVO may activate the cdc2/cyclin B1 complex. Additionally, following EVO exposure, the protein level of unphosphorylated cdc25C (interphase cdc25C, $60 \mathrm{kDa}$ ) was attenuated, and a slower migration form of cdc $25 \mathrm{C}$ (mitotic cdc25C, $75 \mathrm{kDa}$ ) appeared to increase over time (Fig. 2B), which suggested that EVO selectively induced $G_{2} / M$ phase cell cycle arrest by activating the cdc2/cyclin $\mathrm{B} 1$ complex.

EVO induces apoptosis in A-375 cells. Apoptosis was assessed by flow cytometry with Annexin-V/PI staining. As presented in Fig. 3A, the percentage of Annexin-V-FITC-positive cells in A-375 cells exposed to EVO was higher compared with that in DMSO-treated cells, indicating that EVO induced apoptosis in A-375 cells. In addition, compared with those in the DMSO group, activated (cleaved) caspase-3, caspase-9 and PARP1 appeared to increase over time in cells exposed to EVO (Fig. 3B), confirming that EVO induced apoptosis. The protein level of BAX, which is involved in intrinsic apoptosis, was upregulated following EVO treatment (Fig. 3C), and a 

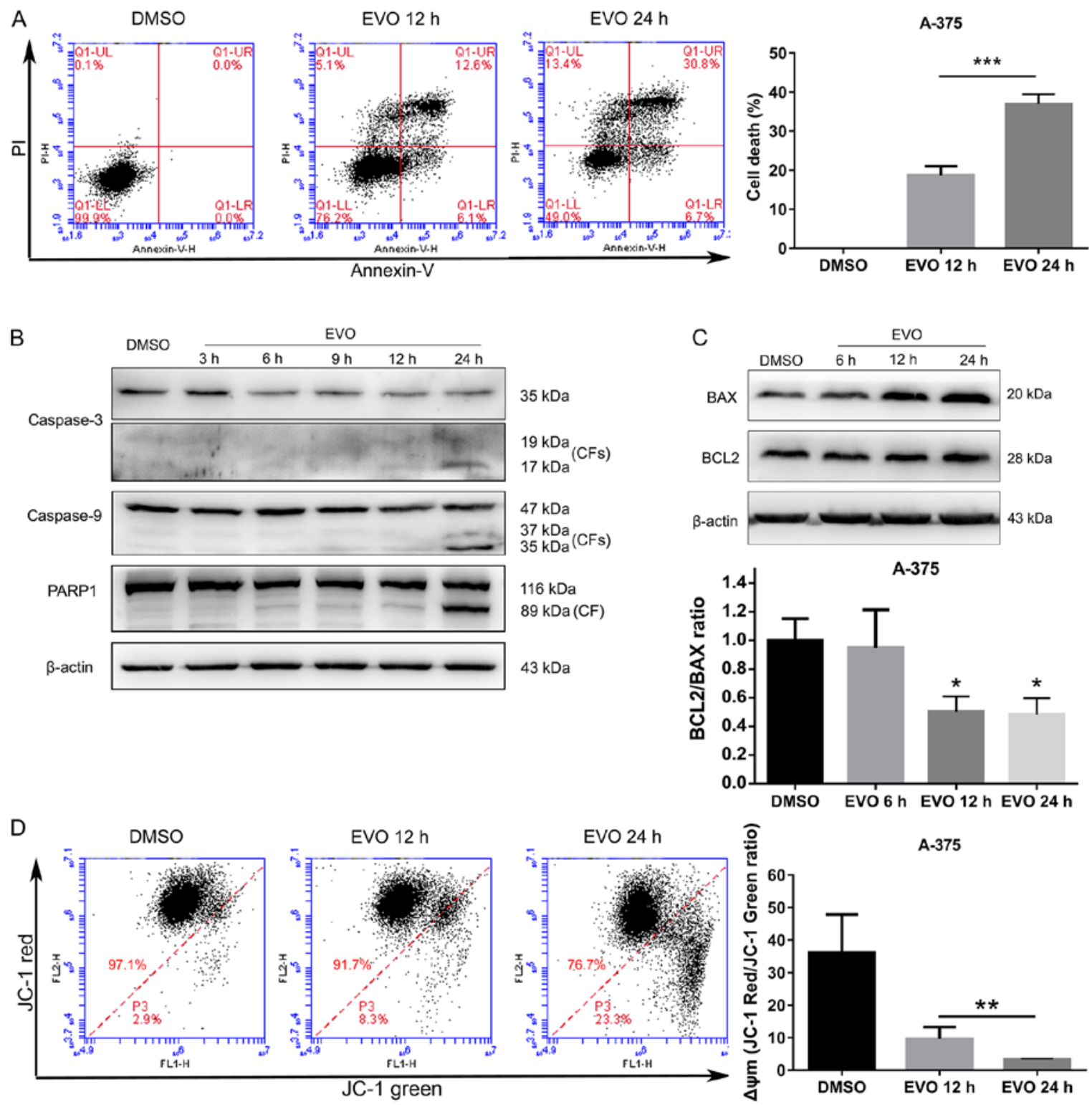

Figure 3. EVO induces apoptosis in A-375 cells. A-375 cells were treated with $10 \mu \mathrm{M}$ EVO for 12 or $24 \mathrm{~h}$. (A) Annexin-V/PI staining assay. The apoptotic rates were examined by flow cytometry. (B) The protein levels of caspase-3, caspase-9, BCL2, BAX and PARP1 were examined by western blotting. (C) The BCL2/BAX protein ratios were calculated. (D) JC-1 assay. The values of $\Delta \psi \mathrm{m}$ were examined by flow cytometry and expressed as the ratio of red to green fluorescence intensity. ${ }^{*} \mathrm{P}<0.05,{ }^{* *} \mathrm{P}<0.01$ and ${ }^{* * * *} \mathrm{P}<0.001$ vs. DMSO. EVO, evodiamine; PI, propidium iodide; PARP1, poly (ADP-ribose) polymerase 1; $\mathrm{CF}$, cleaved form; $\Delta \psi \mathrm{m}$, mitochondrial membrane potential.

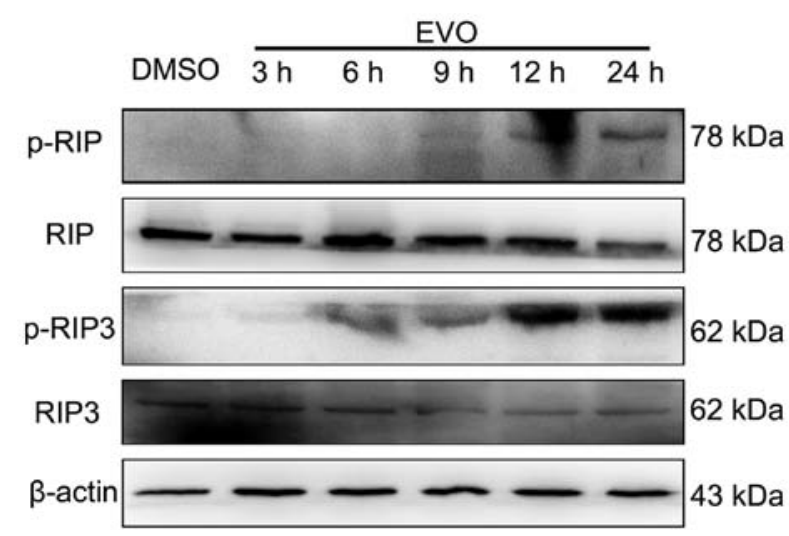

Figure 4. EVO induces necroptosis in A-375 cells. A-375 cells were treated with $10 \mu \mathrm{M}$ EVO for $24 \mathrm{~h}$, and the protein levels of p-RIP, RIP, p-RIP3 and RIP3 were examined by western blotting. EVO, evodiamine; RIP, receptor-interacting serine/threonine kinase. significant decrease in the BCL2/BAX ratio was observed in cells exposed to EVO compared with that in DMSO-treated cells (Fig. 3C), indicating that intrinsic apoptosis may be involved in EVO-induced cell death. EVO exposure also induced significant $\Delta \psi \mathrm{m}$ dissipation compared with that in the DMSO group, indicating that mitochondrial outer membrane permeabilization (MOMP) occurred in A-375 cells exposed to EVO (Fig. 3D).

EVO induces necroptosis in A-375 cells. In addition to apoptosis, the present study examined another type of regulated cell death, necroptosis, which generally manifests with a necrotic morphological type and depends on the sequential activation of RIP, RIP3 and mixed lineage kinase domain-like pseudo kinase (MLKL) $(25,26)$. As presented in Fig. 4, the phosphorylation levels of RIP and RIP3 were increased following 

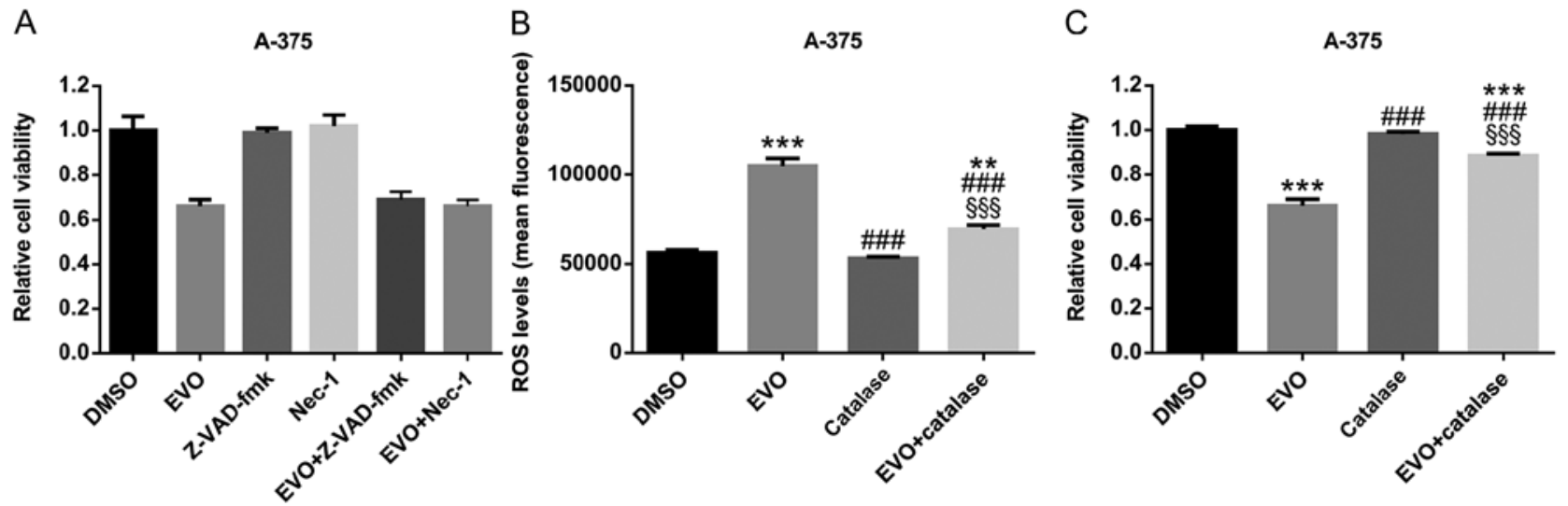

Figure 5. EVO induces ROS-dependent cell death in A-375 cells. (A) Co-treatment with $100 \mu \mathrm{M}$ Z-VAD-fmk or $50 \mu \mathrm{M}$ Nec-1 did not attenuate the $10 \mu \mathrm{M}$ EVO-induced cell death. (B) EVO increased intracellular ROS levels, which were blocked by 2,000 U/ml catalase. (C) Co-treatment with 2,000 U/ml catalase significantly attenuated EVO-induced cell death. ${ }^{* *} \mathrm{P}<0.01$ and ${ }^{* * *} \mathrm{P}<0.001$ vs. DMSO; ${ }^{\# \# \# ~} \mathrm{P}<0.001$ vs. EVO; ${ }^{\S \S} \mathrm{P}<0.001$ vs. catalase. EVO, evodiamine; ROS, reactive oxygen species.

evodiamine treatment, indicating that RIP and RIP3 were activated to precipitate necroptosis in cells exposed to EVO.

EVO induces cell death via ROS generation in A-375 cells. In order to confirm that the apoptosis and necroptosis involved in EVO-induced cell death, the pan-caspase inhibitor Z-VAD-fmk and the RIP1 inhibitor Nec-1 were used, and no significant differences were observed between the EVO and EVO+Z-VAD-fmk or EVO+Nec-1 groups, which revealed that neither Z-VAD-fmk nor Nec-1 attenuated the cytotoxicity of EVO (Fig. 5A). However, this did not suggest that apoptosis or necroptosis was not involved in EVO-induced cell death, but indicated that EVO cytotoxicity was a complicated process.

In order to elucidate the mechanism of cell death induced by EVO in A-375 cells, ROS levels were assessed in the present study. The results revealed that EVO treatment (10 $\mu \mathrm{M}, 24 \mathrm{~h})$ increased ROS generation compared with that in DMSO-treated cells (Fig. 5B). In addition, catalase, which quenches ROS (27), significantly attenuated the EVO-induced ROS generation and consequent cell death (Fig. 5B and C), indicating that ROS may serve an important role in EVO-induced cell death.

\section{Discussion}

EVO, a major quinazoline carboline alkaloid in Evodia rutaecarpa, exerts cytotoxic effects on different types of human cancer cells, including leukemic T-lymphocytes (12), melanoma (13), breast (14), prostate (15), cervical (16), colon (17) and lung (18) cancer cells. However, the underlying mechanism of EVO-induced cell death has not been fully elucidated. The present study investigated the biological effects of EVO in human melanoma A-375 cells.

The effect of EVO on A-375 cell proliferation was assessed using a CCK- 8 assay in the present study, and the results revealed that EVO inhibited cell proliferation in a dose- and time-dependent manner. Several previous studies have proposed that EVO induces cell cycle arrest at the $G_{2} / M$ phase $(15,24,28)$, which was in agreement with the results of the present study. Cell cycle progression is controlled by various classes of cyclins, cyclin-dependent kinases and other regulatory proteins (29). Among them, the activated cdc2/cyclin B complex regulates the progression of the cell cycle from the $G_{2}$ to the $M$ phase (30). In the present study, EVO treatment upregulated the phosphorylation levels of cdc2 at Thr161 compared with those in DMSO-treated cells, but had no effects on the total levels of cdc2 protein, indicating that EVO may activate cdc2. In addition, EVO exposure upregulated cyclin B1 protein levels, which suggested that EVO may induce $\mathrm{G}_{2} / \mathrm{M}$ arrest by activating the cdc2/cyclin B1 complex. Activated cdc $25 \mathrm{C}$ dephosphorylates cdc 2 on Thr14 and Tyr15 and triggers the activation of the cdc2/cyclin B1 complex (31). In the present study, EVO exposure upregulated the levels of p-cdc25C and downregulated the levels of unphosphorylated cdc25C compared with those in the DMSO group, indicating that $\mathrm{cdc} 25 \mathrm{C}$ may be activated by EVO to activate cdc2. These results suggested that EVO may induce $\mathrm{G}_{2} / \mathrm{M}$ phase arrest in A-375 cells by activating the cdc2/cyclin $\mathrm{B} 1$ complex.

Apoptosis, which is a type I form of cell death classified by macroscopic morphological alterations, serves an important role in EVO-induced cell death in colorectal cancer (32) and hepatocellular carcinoma (33) cells; consistently, in the present study, EVO exposure significantly upregulated the apoptotic rate of human melanoma A-375 cells compared with that in DMSO-treated cells. There are two forms of apoptosis, extrinsic and intrinsic, which may be involved in EVO-induced cell death as demonstrated by the results of the present study. Intrinsic apoptosis is also termed 'mitochondrial apoptosis', as irreversible MOMP is the crucial step for intrinsic apoptosis (34). MOMP is controlled by members of the BCL2 apoptosis regulator protein family (35). MOMP is mediated by $\mathrm{BAX}$ and/or BCL2 antagonist/killer 1 in response to apoptotic stimuli (36). By contrast, MOMP is antagonized by antiapoptotic members of the BCL2 family, such as BCL2 (35). In the present study, EVO treatment significantly upregulated the ratio of BCL2/BAX protein levels compared with those in the DMSO-treated control group, indicating that EVO may induce MOMP in A-375 cells. In addition, MOMP directly promotes the cytosolic release of apoptogenic factors normally located in the mitochondrial intermembrane space (36). The released mitochondrial protein somatic cytochrome $\mathrm{c}$ binds to 
apoptotic peptidase-activating factor 1 and pro-caspase-9 to form the supramolecular complex referred to as apoptosome, which is responsible for caspase-9 activation (37). Activated caspase-9 can catalyze the proteolytic activation of executioner caspases, caspase-3 and -7 , which are the enzymes responsible for cell demolition during intrinsic and extrinsic apoptosis in mammalian cells (38). In the present study, EVO treatment induced a significant $\Delta \psi \mathrm{m}$ dissipation and activation of caspase- 9 and caspase-3 compared with that in DMSO-treated cells, indicating that EVO may induce MOMP and consequent intrinsic apoptosis in A-375 cells.

Activation of PARP1 was also observed in A-375 cells exposed to EVO in the present study. PARP1 is a specific component of the DNA damage response machinery, and its activation induces the accumulation of poly (ADP-ribose) polymers and poly (ADP-ribosylated) proteins in the mitochondria, resulting in $\Delta \psi \mathrm{m}$ dissipation and MOMP (39). The binding of the poly (ADP-ribose) polymers to apoptosis-inducing factor mitochondria associated 1 (AIF) promotes the release of AIF into the cytosol and its translocation into the nucleus, where it mediates DNA fragmentation and chromatin condensation (39). This form of cell death induced by the consequent activation of PARP1 and AIF is known as caspase-independent apoptosis, currently termed 'parthanatos' by the Nomenclature Committee on Cell Death (40).

The present study also revealed that in human melanoma A-375 cells, EVO exposure induced the upregulation of RIP and RIP3 phosphorylation compared with that in DMSO-treated cells, indicating that necroptosis may also be involved in EVO-induced cell death. The inhibitors of caspase (Z-VAD-fmk) and RIP (Nec-1) were selected to confirm that apoptosis and necroptosis were involved in EVO-induced cell death in the present study. However, Z-VAD-fmk and Nec-1 both failed to rescue A-375 cells from the cell death induced by EVO. Of note, increasing evidence has indicated that the pharmacologic inhibition of the processes which are commonly considered necessary for cell death execution often does not avoid cellular demise, but alters its biochemical and morphologic manifestations (41). Thus, the inhibitors of caspase (Z-VAD-fmk and broad-spectrum caspase inhibitors), PARP1 and RIP (Nec-1) may fail to reverse cell death induced by pharmacologic interventions despite significantly blocking the activation of caspases, PARP1 and RIP (42-44). However, the proportion of cells eventually succumbing to regulated cell death (RCD) does not change (41). Thus, the results of the present study suggested that Z-VAD-fmk or Nec-1 may block the corresponding cell death phenotype and cause the switch towards another type in EVO-induced cell death.

Early-stage biochemical processes, declining ATP levels and redox alterations in RCD can be reversed to restore cellular homeostasis (41). In the present study, ROS generation was observed in A-375 cells exposed to EVO, and catalase significantly attenuated EVO-induced ROS generation and cell death, which indicated that ROS may serve an important role in EVO-induced cell death. In conclusion, the present study demonstrated that EVO induced apoptosis and necroptosis in human melanoma A-375 cell via a ROS-dependent pathway.

\section{Acknowledgements}

The authors would like to thank Professor Yinlin Ge (Institute of Biochemistry, Medical College, Qingdao University, Qingdao, China) for the help in revising the manuscript.

\section{Funding}

The present study was supported by the Shandong Key R\&D Program (grant no. 2017GSF218084) and the Qingdao Applied Basic Research Program (grant no. 19-6-2-31-cg).

\section{Availability of data and materials}

The datasets used and/or analyzed during the present study are available from the corresponding author on reasonable request.

\section{Authors' contributions}

NL performed the majority of the experiments and analyzed the data. YL assisted with the experiments. GC participated in the analysis, data interpretation and experiment design. $\mathrm{KG}$ designed the experiments and wrote the manuscript. All authors read and approved the final manuscript.

\section{Ethics approval and consent to participate}

Not applicable.

\section{Patient consent for publication}

Not applicable.

\section{Competing interests}

The authors declare that they have no competing interests.

\section{References}

1. Bray F, Ferlay J, Soerjomataram I, Siegel RL, Torre LA and Jemal A: Global cancer statistics 2018: GLOBOCAN estimates of incidence and mortality worldwide for 36 cancers in 185 countries. CA Cancer J Clin 68: 394-424, 2018.

2. Leonardi GC, Falzone L, Salemi R, Zanghì A, Spandidos DA, Mccubrey JA, Candido S and Libra M: Cutaneous melanoma: From pathogenesis to therapy (Review). Int J Oncol 52: 1071-1080, 2018.

3. Lee SH, Son JK, Jeong BS, Jeong TC, Chang HW, Lee ES and Jahng Y: Progress in the studies on rutaecarpine. Molecules 13: 272-300, 2008.

4. Lin H, Tsai SC, Chen JJ, Chiao YC, Wang SW, Wang GJ, Chen CF and Wang PS: Effects of evodiamine on the secretion of testosterone in rat testicular interstitial cells. Metabolism 48: 1532-1535, 1999.

5. Yoshizumi M, Houchi H, Ishimura Y, Hirose M, Kitagawa T, Tsuchiya K, Minakuchi K and Tamaki T: Effect of evodiamine on catecholamine secretion from bovine adrenal medulla. J Med Invest 44: 79-82, 1997.

6. Kobayashi Y: The nociceptive and anti-nociceptive effects of evodiamine from fruits of Evodia rutaecarpa in mice. Planta Med 69: 425-428, 2003

7. Chiou WF, Sung YJ, Liao JF, Shum AY and Chen CF: Inhibitory effect of dehydroevodiamine and evodiamine on nitric oxide production in cultured murine macrophages. J Nat Prod 60: 708-711, 1997.

8. Kobayashi Y, Nakano Y, Kizaki M, Hoshikuma K, Yokoo Y and Kamiya T: Capsaicin-like anti-obese activities of evodiamine from fruits of Evodia rutaecarpa, a vanilloid receptor agonist. Planta Med 67: 628-633, 2001. 
9. Chiou WF, Chou CJ, Shum AY and Chen CF: The vasorelaxant effect of evodiamine in rat isolated mesenteric arteries: Mode of action. Eur J Pharmacol 215: 277-283, 1992.

10. Tsai TH, Lee TF, Chen CF and Wang LC: Thermoregulatory effects of alkaloids isolated from Wu-chu-yu in afebrile and febrile rats. Pharmacol Biochem Behav 50: 293-298, 1995.

11. King CL, Kong YC, Wong NS, Yeung HW, Fong HH and Sankawa U: Uterotonic effect of Evodia rutaecarpa alkaloids. J Nat Prod 43: 577-582, 1980

12. Lee TJ, Kim EJ, Kim S, Jung EM, Park JW, Jeong SH, Park SE, Yoo YH and Kwon TK: Caspase-dependent and caspase-independent apoptosis induced by evodiamine in human leukemic U937 cells. Mol Cancer Ther 5: 2398-2407, 2006.

13. Wang C, Wang MW, Tashiro SI, Onodera S and Ikejima T: Evodiamine induced human melanoma A375-S2 cell death partially through interleukin 1 mediated pathway. Biol Pharm Bull 28: 984-989, 2005.

14. Liao CH, Pan SL, Guh JH, Chang YL, Pai HC, Lin CH and Teng CM: Antitumor mechanism of evodiamine, a constituent from Chinese herb Evodiae fructus, in human multiple-drug resistant breast cancer NCI/ADR-RES cells in vitro and in vivo. Carcinogenesis 26: 968-975, 2005 .

15. Kan SF, Yu CH, Pu HF, Hsu JM, Chen MJ and Wang PS: Anti-proliferative effects of evodiamine on human prostate cancer cell lines DU145 and PC3. J Cell Biochem 101: 44-56, 2007.

16. Fei XF, Wang BX, Li TJ, Tashiro SI, Minami M, Xing DJ and Ikejima T: Evodiamine, a constituent of Evodiae fructus, induces anti-proliferating effects in tumor cells. Cancer Sci 94: 92-98, 2003 .

17. Ogasawara M, Matsubara T and Suzuki H: Inhibitory effects of evodiamine on in vitro invasion and experimental lung metastasis of murine colon cancer cells. Biol Pharm Bull 24: 917-920, 2001.

18. Ogasawara M, Matsunaga T, Takahashi S, Saiki I and Suzuki H: Anti-invasive and metastatic activities of evodiamine. Biol Pharm Bull 25: 1491-1493, 2002.

19. Dickinson BC and Chang CJ: Chemistry and biology of reactive oxygen species in signaling or stress responses. Nat Chem Biol 7: 504-511, 2011

20. Kong Q, Beel JA and Lillehei KO: A threshold concept for cancer therapy. Med Hypotheses 55: 29-35, 2000.

21. Schafer FQ and Buettner GR: Redox environment of the cell as viewed through the redox state of the glutathione disulfide/glutathione couple. Free Radic Biol Med 30: 1191-1212, 2001.

22. Obrador E, Liu-Smith F, Dellinger RW, Salvador R, Meyskens FL and Estrela JM: Oxidative stress and antioxidants in the pathophysiology of malignant melanoma. Biol Chem 400: 589-612, 2019.

23. Wang R, Deng D, Shao N, Xu Y, Xue L, Peng Y, Liu Y and Zhi F: Evodiamine activates cellular apoptosis through suppressing PI3K/AKT and activating MAPK in glioma. OncoTargets Ther 11: 1183-1192, 2018

24. Yang J, Wu LJ, Tashino S, Onodera S and Ikejima T: Protein tyrosine kinase pathway-derived ROS/NO productions contribute to $\mathrm{G} 2 / \mathrm{M}$ cell cycle arrest in evodiamine-treated human cervix carcinoma HeLa cells. Free Radic Res 44: 792-802, 2010.

25. Linkermann A and Green DR: Necroptosis. N Engl J Med 370 455-465, 2014

26. Murphy JM, Czabotar PE, Hildebrand JM, Lucet IS, Zhang JG, Alvarez-Diaz S, Lewis R, Lalaoui N, Metcalf D, Webb AI, et al: The pseudokinase MLKL mediates necroptosis via a molecular switch mechanism. Immunity 39: 443-453, 2013.

27. Glorieux $\mathrm{C}$ and Calderon PB: Catalase, a remarkable enzyme: Targeting the oldest antioxidant enzyme to find a new cancer treatment approach. Biol Chem 398: 1095-1108, 2017.
28. Huang DM, Guh JH, Huang YT, Chueh SC, Chiang PC and Teng CM: Induction of mitotic arrest and apoptosis in human prostate cancer pc-3 cells by evodiamine. J Urol 173: 256-261, 2005.

29. Malumbres M and Barbacid M: Cell cycle, CDKs and cancer: A changing paradigm. Nat Rev Cancer 9: 153-166, 2009.

30. Taylor WR and Stark GR: Regulation of the G2/M transition by p53. Oncogene 20: 1803-1815, 2001.

31. Booher RN, Holman PS and Fattaey A: Human Myt1 is a cell cycle-regulated kinase that inhibits Cdc2 but not Cdk2 activity. J Biol Chem 272: 22300-22306, 1997.

32. Sui H, Zhou LH, Zhang YL, Huang JP, Liu X, Ji Q, Fu XL, Wen HT, Chen ZS, Deng WL, et al: Evodiamine suppresses ABCG2 mediated drug resistance by inhibiting p50/p65 NF-kB pathway in colorectal cancer. J Cell Biochem 117: 1471-1481, 2016.

33. Yang J, Cai X, Lu W, Hu C, Xu X, Yu Q and Cao P: Evodiamine inhibits STAT3 signaling by inducing phosphatase shatterproof 1 in hepatocellular carcinoma cells. Cancer Lett 328: 243-251, 2013.

34. Tait SW and Green DR: Mitochondria and cell death: Outer membrane permeabilization and beyond. Nat Rev Mol Cell Biol 11: 621-632, 2010.

35. Czabotar PE, Lessene G, Strasser A and Adams JM: Control of apoptosis by the BCL-2 protein family: Implications for physiology and therapy. Nat Rev Mol Cell Biol 15: 49-63, 2014.

36. Delbridge AR, Grabow S, Strasser A and Vaux DL: Thirty years of BCL-2: Translating cell death discoveries into novel cancer therapies. Nat Rev Cancer 16: 99-109, 2016

37. Li P, Nijhawan D, Budihardjo I, Srinivasula SM, Ahmad M, Alnemri ES and Wang X: Cytochrome c and dATP-dependent formation of Apaf-1/caspase-9 complex initiates an apoptotic protease cascade. Cell 91: 479-489, 1997.

38. Riedl SJ and Salvesen GS: The apoptosome: Signalling platform of cell death. Nat Rev Mol Cell Biol 8: 405-413, 2007.

39. Fatokun AA, Dawson VL and Dawson TM: Parthanatos: Mitochondrial-linked mechanisms and therapeutic opportunities. Br J Pharmacol 171: 2000-2016, 2014.

40. Galluzzi L, Vitale I, Aaronson SA, Abrams JM, Adam D, Agostinis P, Alnemri ES, Altucci L, Amelio I, Andrews DW, et al: Molecular mechanisms of cell death: Recommendations of the nomenclature committee on cell death 2018. Cell Death Differ 25: 486-541, 2018.

41. Galluzzi L, Bravo-San Pedro JM, Vitale I, Aaronson SA, Abrams JM, Adam D, Alnemri ES, Altucci L, Andrews D, Anni cchiarico-Petruzzelli M, et al: Essential versus accessory aspects of cell death: Recommendations of the NCCD 2015. Cell Death Differ 22: 58-73, 2015

42. Prabhakaran K, Li L, Borowitz JL and Isom GE: Caspase inhibition switches the mode of cell death induced by cyanide by enhancing reactive oxygen species generation and PARP-1 activation. Toxicol Appl Pharmacol 195: 194-202, 2004.

43. Steinhart L, Belz K and Fulda S: Smac mimetic and demethylating agents synergistically trigger cell death in acute myeloid leukemia cells and overcome apoptosis resistance by inducing necroptosis. Cell Death Dis 4: e802, 2013.

44. Dunai ZA, Imre G, Barna G, Korcsmaros T, Petak I, Bauer PI and Mihalik R: Staurosporine induces necroptotic cell death under caspase-compromised conditions in U937 cells. PLoS One 7: e41945, 2012 .

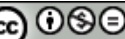

This work is licensed under a Creative Commons Attribution-NonCommercial-NoDerivatives 4.0 International (CC BY-NC-ND 4.0) License. 